\title{
Probiyotik Kaynaklı, Muhtemel Prebiyotik Özelliğe Sahip Ekzopolisakkarit (EPS)'lerin Biyolojik ve Fonksiyonel Özellikleri
}

\author{
Biological and Functional Properties of Possible Prebiotic Properties of \\ Exopolysaccharides (EPSs) from Probiotics
}
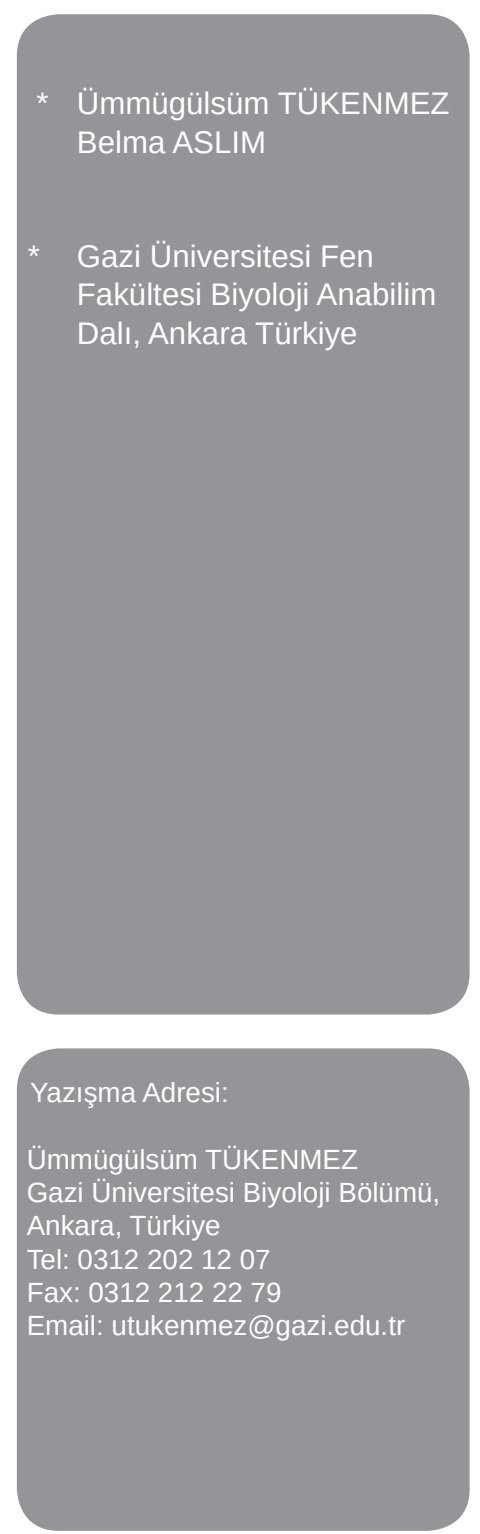

Öz

Son zamanlarda yapılan çalışmalar, ekzopolisakkaritlerin (EPS) ve buların türevi olan oligosakkaritlerin endüstriyel olarak farklı alanlarda kullanılabilme potansiyelini açığa çıkarmıştır. Farklı laktik asit bakterileri (LAB) tarafından üretilen EPS'lerin monomer kompozisyonu, molekül ağılığı ve bağ yapısı gibi yapısal özellikleri, EPS'lerin teknolojik uygulamaları ve biyolojik aktivitelerini etkileyebilmektedir. Literatürlerde, LAB'lar tarafından üretilen EPS'lerin sağlığa faydalı etkileri belirtilmiş ve çeşitli EPS'lerin prebiyotik ve antioksidan özelliğe sahip olabileceği gösterilmiştir. Kanser tedavisinde kullanılan ilaçların doza bağlı olarak toksisite gösterdiği ve güçlü yan etkilere neden olduğu bilinmektedir. Dolayısıyla kanserin tedavisinde etkili ve toksik olmayan veya daha az toksik olan anti-kaser ajanların geliştirilmesine intiyaç duyulmaktadır. LAB'lar gibi güvenilir ve doğal kaynaklardan elde edilen EPS'lerin anti-kanser etkisi ile ilgili çalışmalar artarak devam etmektedir. Dolayısıyla, EPS'lerin sentetik anti-kanser ajanlarına göre daha iyi bir alternatif olabileceği düşünülmektedir. Bu derlemede, LAB'lardan elde edilen EPS'lerin yapısal karakterizasyonu ile biyolojik ve fonksiyonel özellikleri vurgulanarak anti-kanser etkinlikleri belirtilmiştir.

Anahtar Kelimeler: Anti-kanser, antioksidan, ekzopolisakkarit, laktik asit bakterileri, prebiyotik, probiyotik.

\begin{abstract}
Recent studies have revealed the potential of exopolysaccharides (EPS) and their oligosaccharide derivatives for being utilized in various industrial areas. Structural properties of EPSs produced by different lactic acid bacteria (LAB), such as their monomer compositions, molecular weights, and bond structures, may influence their technological applications and biological activities. Studies have indicated that LAB-derived EPSs have beneficial health effects and that various EPSs may have a prebiotic and antioxidant properties. It is already known that drugs used for cancer therapy exert dose-dependent toxicity and cause potent side effects. Hence, there is a need for developing potent but not toxic or less toxic anti-cancer agents. An increasing number of studies have been conducted on the anti-cancer effects of EPSs obtained from reliable and natural sources, such as LABs. Therefore, EPSs are consi-
\end{abstract}


dered to be a better alternative to synthetic anti-cancer agents. This review discusses the structural characterization and biological and functional properties of LAB-derived EPSs and their anti-cancer effects.

Keywords: Anti-cancer, antioxidant, exopolyasccharide, lactic acid bacteria, prebiotic, probiotic.

\section{Giriş}

Probiyotikler, yeterli miktarda alındıklarında konak sağlığına faydalı etkiler gösteren canlı gıda katkıları olarak tanımlanmaktadır ${ }^{(1,2)}$. Laktik asit bakterileri (LAB), LAB dışındaki bazı bakteriler ve bazı mayalar bağırsaklara ulaşana kadar canlı kalabildikleri ve konak sağlığına faydalı etkiler sağladıkları için probiyotik olarak kabul edilmektedirler. LAB, insan gastrointestinal sistemi üzerine faydalı etkileri olduğu bilinen en önemli probiyotiklerdir ${ }^{(3)}$.

$L A B$, genellikle güvenli mikroorganizmalar olarak kabul edilmektedir ve aynı zamanda sağlık riski olmaksızın geniş çeşitlilikte ekzopolisakkaritler (EPS) üretme yeteneğine sahiptirler (4). LAB'dan elde edilen EPS'ler sadece fermente ürünlerin teoloji, tekstür, ağızdaki his ve tadın oluşmasında değil, aynı zamanda anti-tümör, anti-ülser, antioksidan, kolesterol düşürücü ve immün-stimüle edici aktivitelere de sahip olduğu belirtilmiştir (5-7). Ayrıca, EPS'lerin kurumaya, fagositoza, prootozoa tarafından predasyona, faj ataklarına, antibiyotikler veya toksik bileşenlere ve ozmotik stres gibi çeşitli faktörlere karşı koruyucu fonksiyonlara da sahip olabileceği bildirilmiştir. EPS'lerin hücre tanıma, yüzeylere yapışma ve çeşitli ekosistemlere kolonizasyonu kolaylaştırıcı etkiye sahip olduğu ve biyofilm oluşumunda rolü olduğu da bildirilmiştir ${ }^{(8,9)}$. EPS'ler şeker monomerleri ve oligosakkaritlerin bir kaynağı olarak da kullanılabilmektedir ${ }^{(10)}$. LAB, çeşitli fonksiyonel oligosakkaritler de üretelebilmektedir. Bu oligosakkaritlerin, prebiyotik, gıda destekleri, tatlandırıcılar, nemlendiriciler, kolon kanserine karşı ilaç, bağışıklık uyarıcı etki gibi geniş çapta endüstriyel uygulamalara sahip olduğu belirtilmiştir ${ }^{(11)}$.

Kanser, kontrolsüz bölünebilme özelliği göstererek bölünen hücrelerin sayısında giderek artışa neden olan anormal tip bir doku büyümesidir ${ }^{(12-14)}$. Kanser, dünyada birçok ülkede halk arasında görülen hastaIıkların en yaygın gruplarından biridir (15). Günümüzde, kemoterapi uygulamasında kullanılan anti-kanser ajanlar güçlü bir etkinliğe sahip olmakla birlikte, mide bulantısı, kusma ve yorgunluk gibi rahatsızıklar ne- deniyle hastaların yaşam kalitesini düşürmektedir. Ayrıca, bu ajanların güvenliği ve yan etkileri konusunda önemli şüpheler bulunmaktadır (16,17). Kemoterapide kullanılan anti-kanser ilaçların çoğu normal hücrelere de sitotoksiktir ve hastanın iyileşmesini yavaşlatan ve tümör gelişimini etkileyen immünotoksisiteye neden olmaktadır ${ }^{(12)}$. İmmün sistem üzerine düşük yan etkisi olan yeni anti-tümör ilaçların keşfedilmesi ve tanımlanması birçok immünofarmakoloji çalışmasının temel amacı haline gelmiştir ${ }^{(18)}$. LAB gibi güvenli, doğal kaynaklardan elde edilen EPS'lerin, sentetik anti-kanser ajanlarına göre iyi bir alternatif olabileceği belirtilmiștir (19).

\section{Genel Bilgiler}

\subsection{EPS'lerin Yapısı}

Son yıllarda, fizikokimyasal özellikleri ve potansiyel sağlığa faydalı etkilerinden dolayı LAB tarafından üretilen EPS'ler yaygın olarak çalışılmaktadır (20). Farklı LAB tarafından üretilen EPS'lerin komposizyonları, şeker bağları, şeker içerikleri, üç boyutlu yapıları, sertlik, biyokimyasal ve biyofiziksel özellikleri, polimer uzunluğu, polimer dallanmaları, proteinlerle ilişkileri gibi özellikleri de farklılık göstermektedir (21). Çeşitli EPS'lerin yararlıı̆̆ının, EPS'lerin monosakkarit kompozisyonuna, bağların türüne, dallanma derecelerine ve molekül ağırlığına bağlı olduğu belirtilmiştir (22). EPS, dallanmış, tekrarlanan şeker birimlerinden veya şeker türevlerinden oluşmaktadır. Bu şeker üniteleri değişen oranlarda bulunabilmekte ve ağırlıklı olarak glukoz, galaktoz, mannoz, N-asetilglukozamin, N-asetilgalaktozamin ve ramnozdan oluşmaktadır (11). Ayrıca, üronik asit varlığı veya yokluğuna bağlı olarak EPS'ler, sırasıyla asidik veya nötr EPS'ler olarak kategorize edilebilmektedir (23-25).

LAB'dan elde edilen EPS'ler, yüksek oranda çeșitlilik gösteren polimerlerdir ve farklı kriterlere göre sınıflandırılabilmektedirler. En çok kullanılan sınıflandırma kriterlerinden biri, monomer bileşimine dayalı olarak yapılan sınıflandırmadır. Temel olarak tekrarlayan birimlerin bileşimine ve biyosentez yoluna bağlı olarak EPS'ler iki kısımda incelenmektedir. Bunlar; homopolisakkarit (HoPS)'ler ve heteropolisakkarit (HePS)'lerdir (26). HoPS'ler tek tip monosakkaritten, HePS'ler ise birkaç farklı tipte monosakkaritten oluşur (19). HoPS'ler farklı bağ tipi ve dallanma dereceleri ile D-glukoz (glukanlar) veya D-fruktoz (fruktanlar) rezidülerinden oluşmaktadır. HePS'ler ise bir oligosakka- 
ritin çoklu kopyalarından oluşmaktadır ve birbirlerine yapısal olarak çok az benzerlik göstermekte olup genellikle glukoz, galaktoz, ksiloz, mannoz, arabinoz ve ramnoz şekerlerini içermekle birlikte, amino-şekerler, polioller ve glukuronik asiti de bazen içerebilmektedir. HoPS'lerin ortalama molekül ağırlığının genellikle yaklaşık olarak $10^{7} \mathrm{Da}$ olduğu, HePS'lerin molekül ağırlığının ise $10^{4}-10^{6}$ 'Da olduğu belirtilmiştir ${ }^{(27)}$. Bunların dışında, LAB'ın farklı formlarda EPS'ler ürettikleri de belirtilmiştir. Bunlardan biri hücreye bağlı ekzopolisakkarit (hb-EPS) olup, bakteriyel yüzeye bağlı olarak bulunmaktadır. Diğeri ise serbest bırakılan EPS olup (s-EPS) olup, bakterinin bulunduğu ortama bırakılmaktadır (28). EPS üreten LAB suşlarının büyük bir çoğunluğunun s-EPS ürettiği rapor edilmiş, fakat bazı LAB suşlarının aynı anda hem hb-EPS hem de s-EPS üretebildikleri belirtilmiştir. LAB, GRAS (genellikle güvenli kabul edilen) statüsünde bakteriler olarak kabul edildiği için bu bakteriler tarafından üretilen EPS'ler de GRAS statüsünde kabul edilmektedir $(21,29,30)$.

\subsection{EPS' lerin Biyolojik Aktiviteleri}

LAB'dan elde edilen EPS'lerin anti-kanser ve immün-modülatör etkiler olmak üzere iki ana biyo-aktivite sergilediği belirtilmiştir.

\subsubsection{EPS'lerin Anti-Kanser Etkileri}

EPS'lerin anti-kanser biyoaktivitesinin, cMyc, c-Fos ve vasküler endotelyal büyüme faktörü ekspresyonu üzerine olan etkilerini içeren apoptotik ve anti-anjiyogenik özellikler gibi biyolojik mekanizmalar ile gerçekleştiği belirtilmiştir (31). Polisakkaritlerin anti-tümör etki mekanizmasının, esas olarak $T$ ve $B$ lenfositleri, makrofajlar ve NK (Natural Killer) hücrelerinin interlökin salınımını indüklemesi gibi bağışıklık sisteminin bazı bileşenlerini uyarması ile meydana geldiği belirtilmiştir ${ }^{(32,33)}$. Anti-tümör etkiye sahip polisakkaritler, kimyasal bileşimine, konfigürasyonlarına ve fiziksel özelliklerine göre farklılık göstermektedir. Kompleks polisakkaritlerin yapı ve anti-tümör aktivitesini ilişkilendirmenin zor olduğu, ancak bazı ilişkilerin kurulabildiği belirtilmiştir. Glukanın ana zincirindeki $\beta-(1-3)$ bağları ve ek olarak $\beta$-(1-6) dallanma noktaları gibi yapısal özelliklerin, anti-tümör aktivite için gerekli olduğu ve (1-6) bağları içeren $\beta$-glukanların daha az aktiviteye sahip olduğu bildirilmiştir (34). Polisakkaritlerin anti-tümör özelliğinin esas olarak EPS'lerdeki $(1,3)$ bağlantılarından kaynaklandığı belirtilmiştir ${ }^{(35)}$. $\beta-(1,3)$ bağlantıları bulunan EPS'lerin, bağışıklık hücrelerinde bulunan Dectin-1 gibi $\beta$-glukan reseptörüne bağlanmasıyla başlatılan anti-tümör özellik sergilediği bildirilmiştir (36,37). Lactobacillus plantarum'dan elde edilen EPS'nin, MCF-7 hücrelerine anti-tümör etkisi araştırılmış ve bu bileşiğin IC50 değerinin $10 \mathrm{mg} / \mathrm{mL}$ olduğu belirtilmiştir. Ayrıca bu EPS'nin, in vitro koşullarda herhangi bir yan etki göstermediği için gelecekteki çaIışmalar için iyi bir aday olabileceği ve anti-tümör özelliğin ise EPS'deki 1,3 bağlarıyla açıklanabileceği belirtilmiştir ${ }^{(38)}$. L. rhamnosus ATCC 9695'den elde edilen hb-EPS ve s-EPS'nin iki kanser hücre hattı (PANC-1 ve HT-29) üzerinde anti-kanser etkisi araştırılmış ve çalışılan tüm konsantrasyonlarda, EPS'lerin 72 saatte her iki kanser hücre hattının gelişimini baskıladığı, özellikle de $5 \mathrm{mg} / \mathrm{mL}$ konsantrasyonundaki EPS'lerin her iki kanser hücre hattının gelişimini önemli derecede inhibe ettiği, buna karşııı normal hüce hattı üzerinde herhangi bir etki göstermediği belirtilmiştir. Ayrıca, s-EPS'nin, hb-EPS'den daha iyi anti-kanser etki gösterdiği ve EPS'nin anti-kanser etkisinin monosakkarit kompozisyonundan değil de polisakkaritin dallanma tipi gibi yapısal faktörlerden kaynaklanabileceği bildirilmiştir (39). Yapılan başka bir çalışmada, L. helveticus MB2-1'den elde edilen hb-EPS'nin anti-kanser etkisi üç kanser hücre hattı üzerinde (HepG-2, BGC-823, HT-29) araştııılmış ve kontrol olarak da insan kolon epitel hücreleri (HCoEpiC) kullanıımıştır. Çalışma sonucunda, hb-EPS'nin HepG-2 ve BGC-823 hücreleri üzerinde orta düzeyde, HT-29 hücreleri üzerinde ise önemli derecede anti-kanser etki gösterdiği, buna karşılık normal kolon hücreleri üzerinde sitotoksik etki göstermediği belirtilmiştir ${ }^{(19)}$. Başka bir çalışmada ise, Bacillus (EPS-1) ve Pseudomonas (EPS-2) türlerinden elde edilen iki farklı EPS'den, EPS-1'in yüksek şeker konsantrasyonuna, EPS-2'nin ise yüksek protein konsantrasyonuna sahip olduğu belirtilmiştir. Bu iki EPS'nin de doza bağlı olarak tümör hücrelerinin canlılığını azalttığı ve proteinin uzaklaştırılmasından sonra sitotoksik etkinin arttığı gösterilmiştir. Yapısında glukoz ve mannoz içeren spesifik polisakkaritlerin, bağışıklığın aktifleştirilmesi için Toll-like reseptörleriyle hareket edebileceği gösterilmiştir (40). Glukoz ve mannozun makrofajlar üzerinde reseptörlere sahip olduğu ve bu bağlanmanın da anti-kanser aktiviteyi tetiklediği belirtilmiş ve EPS tarafından hücre proliferasyonunun baskılanmasının, apoptozisin indüklenmesi ile olabileceği bildirilmiştir (41).

Polisakkaritlerin moleküler ağırlığının da biyo-aktivitesi üzerinde belirgin bir etkiye sahip olduğu belirtilmiştir. Düşük molekül ağırlıklı polisakkaritlerin, hücre 
zarındaki bariyerleri kolayca geçebileceği ve daha iyi biyolojik aktivite gösterebileceği bildirilmiştir (42). Düşük molekül ağırlıklı kitosan oligossakkaritlerinin, immün sistemin güçlendirilmesi ve kolesterolün düşürülmesi gibi fizyolojik etkilere sahip olduğu belirtilmiştir ${ }^{(43)}$. Yüksek molekül ağırlıkı bazı EPS'ler, dendritik hücreler (DC'ler), makrofajlar ve splenositleri içeren bağışıklık hücrelerinin aktivasyonunu ve belirli sitokinlerin üretimini indüklemektedir. Genel olarak, negatif yüklü EPS ve/veya küçük boyutlu moleküllerin bağışıklık hücrelerinin stimülatörleri olarak davranacağı, buna karşılık, nötr ve büyük boyutlu EPS'lerin ise bastırıcı bir etkiye sahip olabileceği belirtilmiştir (44). Yapılan bazı çalışmalarda da, yüksek molekül ağırlıklı EPS'lerin, belirli aralıklardaki düşük molekül ağırlıklı fraksiyonlara kıyasla daha güçlü anti-tümör aktiviteler gösterdiği belirtilmiştir (45). Yüksek molekül ağırlıklı EPS'nin maksimum anti-tümör aktivite ile ilişkili olduğu rapor edilmiștir (46,47). Tıbbi özelliklere sahip polisakkaritlerin çoğunun, 100 kDa'dan daha yüksek molekül ağırlığına sahip olduğu bildirilmiştir. Ayrıca, biyo-aktivite gösteren Ganoderma lucidum (8 kDa, $22 \mathrm{kDa})$, Euphorbia fischeriana $(49,5 \mathrm{kDa})$ ve ArmilIlariella tabescens (49,5 kDa)'den elde edilen bazı polisakkaritlerin de düşük molekül ağırlığına sahip olduğu belirtilmiştir (48-50). Yapılan başka bir çalışmada, Paenibacillus polymyxa JB115'den elde edilen, farklı molekül ağırlığına sahip $\beta$-glukan içeriği zengin olan EPS'lerin (P-SD-1'in molekül ağırlığı < 100 kDa, P-SD-2'nin molekül ağırlığı > 100 kDa) antioksidan ve anti-tümör aktivitesi araştırılmış ve biyolojik aktivitenin glukanın molekül ağırlığına bağlı olduğu belirtilmiştir (51). Aureobasidium pullulans (siyah maya)'dan elde edilen $\beta$-glukanların (yaklaşık olarak 100 kDa), anti-tümör ve anti-metastatik aktivitelere sahip olduğu bulunmuștur ${ }^{(52)}$. 100-200 kDa molekül ağırlığına sahip $\beta$-glukanların immün düzenleyici fonksiyon gösterdiği belirtilmiştir ${ }^{(53)}$.

\subsubsection{EPS'lerin bağışıklık uyarıcı (immün-stimülatör) etkileri}

Polisakkaritlerin immün düzenleyici biyo-aktivitesi ile ilgili önemli bir özelliğin yapı ve fonksiyon ilișkisi olduğu belirtilmiştir. Polisakkaritlerin molekül ağırlığı, tersiyer yapısı veya yapı ve kompozisyonu biyolojik aktivitesini etkileyebilmektedir. Genel olarak, $\beta-(1,3)$, $\beta-(1,4)$ veya $\beta-(1,6)$ bağları ile dallanmış zincirler içeren polisakkaritlerin aktivite için gerekli olduğu bildirilmiștir. Anyonik yapılar ve daha yüksek molekül ağırlıklı kompleks dallanmış zincirli polisakkaritlerin daha iyi immün-stimüle edici aktiviteye sahip olduğu belirtilmiștir (54). $\beta$-glukanlar (C-2 konumunda 1-3 bağlantısı ile) in vitro olarak makrofajların immün-modülasyonunu yapabileceği bildirilmiştir ${ }^{(55,56)}$. Biyo-aktivite farklılıklarının, hücre yüzeyinde reseptör afinitesi veya reseptör-ligand etkileşimlerinin farklılıklarından olabileceği belirtilmiştir ${ }^{(57)}$.

Yapılan bazı çalışmalar, probiyotik bakteriler tarafından üretilen EPS'lerin sistemik ve mukozal immün cevabı modüle edebildiğini ve dolayısıyla doğrudan sağlığı teşvik edici avantajlar sağladığını göstermektedir. Dolayısıyla, Bifidobacterium, Lactobacillus, Lactococcus ve Leuconostoc gibi çeşitli LAB türlerinden elde edilen EPS'lerin, immün-modülatör aktivitede önemli bir rol oynadığı bulunmuştur ${ }^{(58)}$. LAB'dan elde edilen EPS'ler, bileşiminde geniş bir heterojenlik göstermektedir. Dolayısıyla, EPS'lerin biyolojik özelliklerinin suşa bağlı olduğu belirlenmiş ve bu nedenle, etki mekanizmalarının yalnızca bir kısmı aydınlatılabilmiştir. Yüksek moleküler ağırlıkı bazı EPS'lerin, dendritik hücreler (DC'ler), makrofajlar ve splenositleri içeren bağışıklık hücrelerinin aktivasyonunu indükleyebileceği ve spesifik sitokinlerin üretimini uyarmak için kullanılabileceği belirtilmiştir ${ }^{(44)}$. Yapılan bazı çalışmalar da, düşük molekül ağırlıklı EPS'lerin yüksek moleküler ağırlıklı EPS'lere göre daha iyi immün-modülatör etkilere sahip olabileceği gösterilmiştir ${ }^{(59)}$. Yapılan başka bir çalışmada, yumuşak beyaz peynirden izole edilen probiyotik Lactobacillus paraplantarum BGCG1 suşunun, hem bağışıklığın düzenlenmesinde etkili olan hem de viskoz yapının oluşumundan sorumlu olan yüksek molekül ağırlıklı HePS ürettiği ve bu HePS'nin $\%$ 86,6 glukoz, \% 6,2 mannoz, \% 4,1 galaktoz ve \% 3,1 ramnozdan oluştuğu bildirilmiştir ${ }^{(60)}$. LAB'leri tarafından üretilen HePS'lerin, immün-stimülatör aktiviteye sahip olduğu bildirilmiştir. Leuconostoc mesenteroides NTM048'in, 10-40 kDa boyutlarında, glukoz ve fruktoz birimlerini içeren HePS'ler ürettiği belirtilmiş ve bu HePS'nin in vitro koşullarda, Peyer's Patch hücrelerinin total ve antijene spesifik IgA üretimini indüklediği ve splenositlerde, Th1 ve Th2 hücre aracıIı reaksiyonu etkilediği gösterilmiştir (61). Lactococcus lactis ssp. cremoris KVS20'den elde edilen EPS'nin, makrofajlarda lenfosit mitojenisitesi (62), makrofaj sitostatikliği ve sitokin (IFN-y ve IL-1 $\beta$ ) üretimi gibi biyo-aktiviteler sergilediği gösterilmiştir ${ }^{(63)}$.

Hayvan modelleri ile yapılan bazı in vivo çalışmalar, LAB tarafından üretilen EPS'lerin patojenlere karşı koruma düzeyini artırabildiğini açıkça göstermiştir. Yapı- 
Ian bir çalışmada, Bacteroides fragilis'ten elde edilen polisakkaritlerin, IL-17 üretimini baskılayarak ve IL-10 üretimi için düzenleyici T hücrelerini uyararak, Helicobacter hepaticus tarafından indüklenen deneysel kolite karşı hayvanları koruduğu gösterilmiştir ${ }^{\left({ }^{64)}\right.}$. Buna ek olarak, L. rhamnosus RW-9595M'den elde edilen yüksek molekül ağırlıkı EPS'nin, makrofajlar ve lenfositlerde düşük seviyede pro-inflamatuvar mediatörlere neden olduğu, immün düzenleyici sitokin olan IL-10 üretimini arttırdığı bildirilmiştir ${ }^{(65)}$. LAB'dan elde edilen bazı EPS'lerin anti-inflamatuvar özelliği, makrofajların duyarsızlaşmasını tetiklemek için kullanılmıştır. EPS ile muamele edilen makrofajların LPS (lipopolisakkarit) ile yeniden uyarıldıktan sonra TNF- $\alpha$ üretimini azalttığı gösterilmiştir (66). Yapılan bazı çalışmalarda ise, LAB'dan elde edilen EPS'lerin immün-stimülatör etkileri gösterilmiştir. L. parakasei suşundan elde ediIen EPS'nin, murin RAW makrofajlarında IL-6, IL-1 $\beta$ ve TNF- $\alpha$ üretimini indükleme kabiliyetine sahip olduğu belirtilmiştir ${ }^{\left({ }^{67}\right)}$. In vitro koşullarda yapılan bir çalışmada, fosfat grupları (negatif yük) içeren HePS'lerin, dalak makrofajlarında TNF- $\alpha$ ve IL-1 $\alpha$ sentezini uyararak immün cevabı iyi bir şekilde indükledikleri bildirilmiştir (63). Buna ek olarak, LAB suşlarından elde edilen asidik ve nötr EPS'lerin immün-modülatör aktivitelerinde dikkate değer farklııklar bulunduğu da belirtilmiştir. L.bulgaricus OLL1073-R1'den elde edilen asidik EPS'nin in vivo ve in vitro koşullarda makrofaj fonksiyonunu artırdığı, nötr EPS'nin ise yalnızca in vitro koşullarda zayıf etki gösterdiği bildirilmiştir. Asidik EPS'nin çeşitli sitokinlerin üretilmesine neden olarak makrofajların güçlü bir uyarıcısı olduğu belirlenmiş ve bu etkinin, asidik EPS'den fosfor çıkarıldıktan sonra önemli ölçüde azaldığı bildirilmiştir ${ }^{(68,69)}$.

\subsection{EPS'lerin Fonksiyonel Özellikleri}

Probiyotiklerden elde edilen EPS'lerin prebiyotik $(25,70)$ ve antioksidan etkiler ${ }^{(71,72)}$ gibi sağlığa faydalı etkileri de literatürlerde bildirilmiştir.

\subsubsection{EPS'lerin Prebiyotik Özellikleri}

Prebiyotikler, intestinal sistemde yararlı bakterilerin (probiyotiklerin) büyümesini teşvik ederek sağıığa faydalı etkiler göstermekte ${ }^{(73)}$ ve bağırsaktaki adenomlar ve karsinomlar gibi lezyonların büyümesi engelleyerek kolorektal hastalıkların oluşumunda rol oynayan risk faktörlerini azaltmaktadır (74). Bakteriyel EPS'ler, insan gastrointestinal sindirimine karşı yüksek direnç göstermekte ve probiyotik bakterilerin gelişmesi için karbon kaynağı olarak kullanılan fruktooligosakkarit, galaktooligosakkarit ve inülin gibi diğer ticari prebiyotiklere benzer şekilde, kolonda kolonize olmuş faydalı bakterilerin seçici olarak zenginleştirilmesini sağlamaktadır ${ }^{(75)}$. Çok sayıda EPS, prebiyotik aktivitelerinden dolayı araştırılmıştır (3,76). Lactobacillus plantarum, Weissella cibaria, Weissella confusa ve Pediococcus pentosaceus'dan elde edilen EPS'lerin Bifidobacterium bifidum DSM 20456 tarafından karbon kaynağı olarak kullanılabileceği rapor edilmiştir (75). Lactobacillus plantarum YW32'den elde edilen HePS'lerin, çeşitli patojen bakterilere karşı antibiyofilm aktivite ve insan kolon kanseri (HT-29) hücrelerine karşı anti-tümör aktivite gösterdiği belirtilmiştir. Bu HePS'nin, reolojik özellikleri iyileştirmek için gıdalarda uygulanmasını kolaylaştıran ağ benzeri bir mikroyapıya sahip olduğu taramalı elektron mikroskobu ile belirlenmiştir. Ayrıca, bu HePS'nin termal olarak stabil olduğu, yüksek bozunma sıcaklığına $\left(283,5^{\circ} \mathrm{C}\right)$ sahip olduğu da belirtilmiştir (72). Tibet kefirinden izole ediIen Lactobacillus plantarum SKT109'dan elde edilen HePS'nin, yaklaşık olarak 3:1 molar oranında fruktoz ve glukoz monomer birimlerinden oluştuğu ve ortalama molekül ağırığının $2,1 \times 10^{6} \mathrm{Da}$ olduğu belirtilmiştir (77). Probiyotik $L$. plantarum RFJ,'den elde edilen HePS'nin, glukoz ve mannoz şeker rezidülerinden oluştuğu, $225^{\circ} \mathrm{C}^{\prime}$ ye kadar toleranslı olduğu ve antioksidan, kolesterol düşürücü, anti-diabetik aktiviteler sergilediği de bildirilmiştir. Bu HePS'nin, pankreatik kanser hücre hattı (MiaPaCa2) ve kolon karsinoma hücre hattı (DLD2) gibi kanser hücre hatlarını inhibe ettiği ve fare fibroblast hücre hattı (L929 hücreleri) gibi normal hücre hatları için toksik olmadığı gösterilmiştir (71). L. plantarum TISTR 875'den elde edilen HePS'nin de insan kolonunun oldukça rekabetçi koşulları altında, bifidobakteriler ve laktobasiller gibi probiyotiklerin büyümesini seçici bir şekilde artırdığı gösterilmiştir ${ }^{(75)}$. Bu bulgular, LAB'dan elde edilen HePS'lerin, potansiyel olarak gıda endüstrisinde prebiyotik bir bileşen olarak kullanılabileceğini göstermektedir ${ }^{(70)}$.

\subsubsection{EPS'lerin Antioksidan Özellikleri}

LAB'lardan elde edilen EPS'lerin, antioksidan aktivitelerinden dolayı gıda ve fermentasyon endüstrilerinde faydalı olabileceği belirtilmiştir. HePS'lerin, güçlü bir antioksidan olan askorbik asit ile kıyaslanarak antioksidan özelliğe sahip olduğu gösterilmiștir (70,71). LAB'den elde edilen birkaç HePS'nin antioksidan aktivitesi değerlendirilmiş ve monosakkarit bileșiminin, HePS'nin antioksidan aktivitesi üzerinde önemli bir et- 
kiye sahip olabileceği tespit edilmiştir (71). D-galaktoz, fruktoz, arabinoz ve mannoz gibi nötr monosakkarit içeriği fazla olan polisakkaritlerin daha yüksek antioksidan aktiviteye sahip olduğu bildirilmiştir. Özellikle de nötr D-galaktoz molekülünü içeren HePS'lerin, antioksidan aktivite gösterdiği belirlenmiştir. Buna karşılık, L. plantarum RJF4'ten elde edilen HePS'nin herhangi bir D-galaktoz molekülüne sahip olmadığı, ancak nötr monosakkarit olarak mannozu içerdiği ve DPPH radikali süpürme aktivitesi gösterdiği belirlenmiştir $(\% 22,63)$. L. plantarum C88'den ve L. plantarum YW32'den elde edilen ve D-galaktoz içeren HePS'nin daha yüksek DPPH radikali süpürme aktivitesi gös-

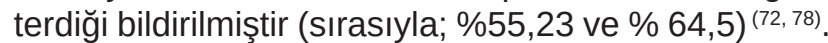
L. plantarum C88'den elde edilen HePS (LPC-1)'nin, in vitro koşullarda, Caco-2 hücrelerinde hidrojen peroksit $\left(\mathrm{H}_{2} \mathrm{O}_{2}\right)$ ile indüklenen hasarlara karşı önemli bir antioksidan aktivite gösterdiği bildirilmiştir (79).

\subsection{EPS' lerin Anti-Kanser Etki Mekanizması}

Apoptoz, genetik olarak programlanmış bir hücre ölümü biçimidir ve hücre sayılarının düzenlenmesinde anahtar rol oynamaktadır (80,81). Birçok kanser türünün önemli bir patogenetik olayı, hücre proliferasyonunun kontrol süreçlerinin değiştirilmesine bağlı olarak apoptozu tetikleme yeteneğinin azalmasıdır (82). Hücrenin hayatta kalması ve moleküler düzeyde ölümün apoptotik süreç üzerinden düzenlenmesinin terapötik potansiyele sahip olabileceği belirtilmiştir ${ }^{(83)}$. Birkaç epidemiyolojik ve deneysel çalışmalar, spesifik $L A B$ suşlarının veya fermente süt ürünlerinin tüketilmesinin, bazı kanser risklerini azalttığını ve tümör gelişimini inhibe ettiğini göstermiştir (84).

İyi bilinen bir ölüm yolağı olan apoptoza (programlanmış hücre ölümü tip I) ilaveten, otofaji olarak adlandırılan, ilginç bir programlanmış hücre ölüm yolağı da tanımlanmıştır (programlanmış hücre ölümü tip II). Otofaji, besin yoksunluğu sırasında tipik olarak gözlenen, uzun ömürlü protein bozunmasının dinamik bir süreci olarak belirtilmiștir (85). Kanser hücrelerinin farkI tipleri çeşitli anti-kanser tedavileri sonrasında otofajiye geçtiği için otofajiye olan ilgi de artmıştır ${ }^{(86)}$. Probiyotik bakterilerden elde edilen birkaç kanser önleyici bileşen, çeşitli kanserlerin potansiyel olarak önlenmesi için aday olarak önerilmiştir ${ }^{(87,88)}$. Bununla birlikte, bu bileşenlerin kanser hücrelerini etkileme mekanizmaları, genetik ve proteomik seviyelerde açıça anlaşılamamıştır. Proteomik analize dayalı olarak, Beclin-1 ve GRP78'in de dahil olduğu otofajik hücre ölümünde rol alan birkaç proteinin, hb-EPS tarafından belirgin bir şekilde düzenlendiği belirtilmiştir. Beclin-1, memelilerde bulunan bir otofaji proteini iken, GRP78 (BiP olarak da bilinir), endoplazmik retikulum (ER)'un moleküler şaperonudur. Her iki proteinde de ER stresine eşlik eden otofajiye bağlı hücre ölüm yolağında önemli rol oynamaktadır ${ }^{(89)}$. Son zamanlarda yapılan çalışmalar otofajinin, ER stresinde hücre sağkalımı için savunma mekanizması olarak aktive gösterdiğini belirtmiştir ${ }^{(90)}$. Beclin-1'in, ER stresi kaynaklı otofaji için gerekli olduğu ve GRP78'in ise insan hücrelerinde ER stresi kaynaklı otofajiyi düzenlediği bildirilmiştir. Ayrıca, RNA interferensi ile GRP78'in yok edilmesinin, besin yoksunluğu veya ER stresiyle başlatılan otofagozom oluşumunun belirgin bir şekilde bastırılmasına yol açtığı gösterilmiştir ${ }^{(89)}$. Bu nedenle, hücreye bağlı EPS uygulamasının, Beclin-1'in ekspresyonu ile ortaya çıkan bir kaskad tarafından otofaji ile ilişkili kanser hücresi ölümünü destekleyen ER stresini ve GRP78 ekspresyonunu indüklemesi ile mümkün olabileceği belirtilmiştir. Buna ek olarak, strese bağlı proteinlerin, hasar gören proteinlerin yeniden katlanması ve proteinin hücre canlıığı için önemli prosesler olan mitokondriye aktarılarak hücre sağkalımı için önemli proseslere dahil olduğu gösterilmiştir (91). Dolayısıyla, hb-EPS'nin, stres kaynaklı protein sayısını uyardığı ve normal hücresel morfolojisinin korunmasında önemli olan proteinleri etkilediği gösterilmiştir (7). Beclin-1 ve GRP78'e ek olarak, Bcl-2'nin de dahil olduğu, apoptoz ile ilişkili proteinlerin otofajide de rol oynayabileceği belirtilmiştir ${ }^{(92)}$. Beclin1 / Bcl-2 etkileşimleri hem apoptozla hem de otofajiye bağlı ölümle sonuçlanabilmektedir (93). Ayrıca, Bak'ın otofajiyi baskılayıcı olarak rol oynadığı gösterilmiştir ${ }^{(94)}$. Ayrıca, hücreye bağlı EPS'nin, Bcl-2'yi bastıırken, Beclin-1 ve Bak'ı indüklediği belirtilmiştir (7). Pro-apoptotik (Bak gibi) ve anti-apoptotik (Bcl-2 gibi) proteinler arasındaki dengenin, otofajinin bir düzenleyicisi olarak rol oynayabileceği bildirilmiştir ${ }^{(94)}$. Beclin-1, Bcl-2 ve Bak arasındaki denge veya oranın, otofaji yoluyla hb-EPS'nin anti-tümör aktivitede önemli bir rol oynayabileceğini göstermektedir (7). Bu sonuçlar, EPS'lerin hem apoptoz hem de otofajide birden çok gen ve protein üzerinde çoklu mekanizmalarda etkili olduğunun kanıtı niteliğindedir.

\section{Sonuç}

Mikrobiyal EPS'ler, çeșitli biyolojik özelliklerinden dolayı özellikle gıda, süt ve kozmetik endüstrileri gibi çeşitli endüstrilerde oldukça fazla ilgi görmektedir. Aynı zamanda, tıp ve ilaç endüstrilerinde de kullanılmakta 
ve kontrollü ilaç salınımlı formülasyonda önemli araçlar haline gelmiştir. Polisakkaritlerin yapısal özellikleri ile fonksiyonel özellikleri arasında pozitif bir ilişki bulunduğu için LAB'dan elde edilen EPS'lerin yapısal karakterizasyonu oldukça önem arz etmektedir. EPS'lerin kimyasal yapıları farklılık göstermektedir ve herhangi bir spesifik fonksiyonel özellik ile EPS'lerin kimyasal yapısı arasında pozitif bir ilişkinin olduğu yapılan literatür taramalarında görülmüştür. Mikrobiyal kökenli EPS'ler geniş kimyasal çeşitlilik sergilemekte ve farklı türler tarafından üretilebilmektedir. Probiyotiklerden elde edilen EPS'ler, hem sağlığa faydalı etkilerinden dolayı hem de doku ve reoloji gibi gıdalardaki organoleptik yapıyı geliştirici etkilerinden dolayı fonksiyonel gıdaların eldesinde çok iyi bir aday olduğu belirtilmiştir. Yapılan literatür taramalarından elde edilen bulgular, EPS'lerin normal hücrelere karşı toksik olmadığını ve suda çözünebilir olduğunu ve anti-kanser etkilerinin varlığını göstermektedir. Kanserin tek bir mekanizma üzerinden değil multi mekanizmalarla etkili olarak geliştiği bilinmektedir. EPS'lerin de hem apoptotik hem de otofajik yolaklarda çoklu gen ve proteinleri etkileyerek anti-kanser özellik gösterdiğinin tespit edilmiş olması, alternatif bir terapötik ajan olabilme potansiyelini arttırmaktadır. Bu özellikler EPS'lerin anti-kanser ajanı olarak kullanılabileceğinin göstergesidir. Bu derlemede sunulan bulgular, LAB gibi güvenli ve doğal kaynaklardan elde edilen EPS'lerin, kansere karşı uzun süreli tedavi süreçlerinde, zararlı yan etkileri olmaksızın sentetik anti-tümör ajanlarına iyi bir alternatif olabileceğini göstermektedir.

\section{Kaynaklar}

1-Salminen S, Bouley C, Boutron-Ruaultetal MC. Functional food science and gastrointestinal physiology and function. Br J Nutr 1998; 80 (1): 147-171.

2-FAO/WHO. 2001. Reporton Joint FAO/WHO Expert Consultationon Evaluation of Health and Nutritional Properties of Probiotics in Food Including Powder Milk with Live Lactic Acid Bacteria.

3-Hussein MDM, Ghaly MF, Osman MY, Al Shimaa GS, Helal MM. Production and prebiotic activity of exopolysaccharides derived from some probiotics. Egypt Pharmaceut J 2015; 14 (1): 1.

4-Surayot U, Wang J, Seesuriyachan P, Kuntiya A, Tabarsa M, Lee Y, Kim JK, Park, W, You S. Exopolysaccharides from lactic acid bacteria: structural analysis, molecular weight effect on immunomodulation. Int $\mathrm{J}$
Biol Macromol 2014; 68: 233-240.

5-Van Calsteren MR, Pau-Roblot C, Bégin A, Roy D. Structure determination of the exopolysaccharide produced by Lactobacillus rhamnosus strains RW-9595M and R. Biochemical Journal 2002; 363: 7-17.

6-Doleyres Y, Schaub L, a Lacroix C. Comparison of the functionality of exopolysaccharides produced in situ or added as bioingredients on yogurt properties. J Dairy Sci 2005; 88: 4146-4156.

7-Kim Y, Oh S, Yun HS, Kim SH. Cell-bound exopolysaccharide from probiotic bacteria induces autophagic cell death of tumour cells. Lett Appl Microbiol 2010; 51 (2): 123-130.

8-Looijesteijn PJ, Trapet L, de Vries E, Abee T, Hugenholtz J. Physiological function of exopolysaccharides produced by Lactococcus lactis. Int J Food Microbiol 2001; 64: 71-80.

9-Whitfield C, Valvano MA. Biosynthesis and expression of cell-surfaces polysaccharides in gram-negative bacteria. Adv Microb Physiol 1993; 35: 135-146.

10-Freitas F, Alves VD, Reis MA. Advances in bacterial exopolysaccharides: from production to biotechnological applications. Trends Biotechnol 2011; 29: 388-398.

11-Patel S, Majumder A, Goyal A. Potentials of exopolysaccharides from lactic acid bacteria. Indian $\mathrm{J}$ Microbiol 2012; 52: 3-12.

12-Zandi K, Tajbakhsh S, Nabipour I, Rastian Z, Yousefi F, Sharafian S, Sartavi K. In vitro antitumor activity of Gracilaria corticata (a red alga) against jurkat and molt-4 human cancer cell lines. Afr J Biotechnol 2010; 9: 6787-6790.

13-Kanchana A, Balakrishna M. Anti-cancer effect of saponins isolated from solanum trilobatum leaf extract and induction of apoptosis in human larynx cancer cell lines. Int J Pharm Pharm Sci 2011; 3: 356-364.

14-Hemamalini K, Soujanya GL, Bhargav A, Vasireddy $U$. In-vivo anticancer activity of Tabebuia rosea (bertol) dc. leaves on Dalton's ascetic lymphoma in mice. Int J Pharm Sci Res 2012; 3: 4496-4502. 
15-Jemal A, Siegel R, Ward E, Murray T, Xu J, Smigal C, Thun M. Cancer stat, 2006. CA Cancer J Clin 2006; 56: 106-130.

16-Adamsen L, Quist M, Midtgaard J, Andersen C, Moller T, Knutsen L, Tveteras A, Rorth M. The effect of a multidimensional exercise intervention on physical capacity, well-being and quality of life in cancer patients undergoing chemotherapy. Support Care Cancer 2006, 14, 116-127.

17-Wagner AD, Grothe W, Haerting J, Kleber G, Grothey A, Fleig WE. Chemotherapy in advanced gastric cancer: A systematic review and meta-analysis based on aggregate data. J Clin Oncol 2006; 24, 2903-2909.

18-Abd El Ghany K, Hamouda R, Abd Elhafez E, Mahrous H, Salem-Bekhit M, Hamza HA. A potential role of Lactobacillus acidophilus LA1 and its exopolysaccharides on cancer cells in male albino mice. Biotechnol Biotechnol Equip 2015; 29 (5): 977-983.

19-Li W, Xia X, Tang W, Ji J, Rui X, Chen X, Jiang M, Zhou J, Zhang Q, Dong M. Structural characterization and anticancer activity of cell-bound exopolysaccharide from Lactobacillus helveticus MB2-1. J Agric Food Chem 2015; 63 (13): 3454-3463.

20-Degeest B, Mozzi F, De Vuyst L. Effect of medium composition and temperature and $\mathrm{pH}$ changes on exopolysaccharide yields and stability during Streptococcus thermophilus LY03 fermentations. Int J Food Microbiol 2002; 79: 161-174.

21-Welman AD, Maddox S. Exopolysaccharides from lactic acid bacteria: perspectives and challenges. Trends Biotechnol 2003; 21: 269-274.

22-Iliev I, Ivanova I, Ignatova C. Glucansucrases from lactic acid bacteria (LAB). Biotechnol Biotechnol Equipment 2006; 3: 15-20.

23-Cragg GM, Newman DJ, Snader KM. Natural products in drug discovery and development. J Nat Prod 1997; 60: 52-60.

24-Madhuri KV, Vidya Prabhakar K. Microbial exopolysaccharides: biosynthesis and potential applications. Oriental J Chem 2014; 30: 14011410.

25-Ramana KV, Xavier JR, Sharma RK. Recent Trends in pharmaceutical biotechnology. Pharmaceutical
Biotechnology: Current Research 2017; 1 (1): 5.

26-Mende S, Rohm H, Jaros D. Unfluence of exopolysaccharides on the structure, texture, stability and sensory properties of yoghurt and related products. Int Dairy J, 2016; 52: 57-71.

27-Kristo E, Miao Z, Corredig M. The role of exopolysaccharides produced by Lactococcus lactis subsp. cremoris in structure formation and recovery of acid milk gels. Int Dairy J 2011; 21: 656-662.

28-Yang Z, Li S, Zhang X, Zeng X, Li D, Zhao Y, Zhang J. Capsular and slime-polysaccharide production by Lactobacillus rhamnosus JAAS8 isolated from Chinese sauerkraut: Potential application in fermented milk products. J Biosci Bioeng 2010; 110: 53-57.

29-Kleerebezem M, Hugenholtz J. Metabolic pathway engineering in lactic acid bacteria. Curr Opin Biotechnol 2003; 14: 232-237.

30-Kleerebezem M, Boels IC, Groot MN, Mierau I, Sybesma W, Hugenholtz J. Metabolic engineering of Lactococcus lactis: the impact of genomics and metabolic modelling. J Biotechnol 2002; 98: 199-213.

31-Yang J, Zhang W, Shi P, Chen J, Han X, Wang $Y$. Effects of exopolysaccharide fraction (EPSF) from a cultivated Cordyceps sinensis fungus on C-Myc, c-Fos, and VEGF expression in B16 melanoma-bearing mice. Pathol Res Prac 2005; 201: 745-750.

32-Wasser SP. Medicinal mushrooms as a source of antitumor and immunomodulating polysaccharides. Appl Microbiol Biotechnol 2002; 60: 258-274.

33-Lin ZB, Zhang HN. Anti-tumor and immunoregulatory activities of Ganoderma lucidum and its possible mechanisms. Acta Pharmacol Sin 2004; 25: $1387-$ 1395.

34-Mizuno T. The extraction and development of antitumor-active polysaccharides from medicinal mushrooms in Japan. Int J Med Mushrooms 1999; 1: 105119.

35-Ismail B, Nampoothiri KM. Production, purification and structural characterization of an exopolysaccharide produced by a probiotic Lactobacillus plantarum MTCC 9510. Arch Microbiol 2010; 192: 1049-1057.

36-Brown GD, Gordon S. Immune recognition. A new 
receptor for $\beta$-glucans. Nature 2001; 413: 36-37.

37-Taylor PR, Brown GD, Reid DM, Willment JA, Martinez Pomares L, Gordon S, Wong SY. The $\beta$-glucan receptor, dectin-1, is predominantly expressed on the surface of cells of the monocyte/macrophage and neutrophil lineages. J Immunol 2002; 169: 38763882.

38-Ismail B, Nampoothiri KM. Exposition of antitumour activity of a chemically characterized exopolysaccharide from a probiotic Lactobacillus plantarum MTCC 9510. Biologia 2013; 68 (6): 1041-1047.

39-Kim JU, Kim Y, Han KS, Oh S, Whang KY, Kim $\mathrm{JN}$, Kim SH. Function of cell-bound and released exopolysaccharides produced by Lactobacillus rhamnosus ATCC 9595. J Microbiol Biotechnol 2006; 16 : 939-945.

40-Shao BM, Dai H, Xu W, Lin ZB, Gao XM. Immune receptors for polysaccharides from Ganoderma lucidum. Biochem Biophys Res Commun 2004; 323 133-141.

41-Vidhyalakshmi R, Vallinachiyar C. Apoptosis of human breast cancer cells (MCF-7) induced by polysaccharides produced by bacteria. J Cancer Sci Ther 2013; 5: 31-34.

42-Li S, Xiong Q, Lai X, Li X, Wan M, Zhang J, Yan Y, Cao M, Lu L, Guan J, Zhang D, Lin Y. Molecular modification of polysaccharides and resulting bioactivities. Compr Rev Food Sci Food Saf 2016; 15 (2): 237-250.

43-Lai SL, Pan ZY, Li XF. Study on the degradability of chitosan under microwave irradiation. J. Shanxi Univ Sci Technol 2005; 23: 38-40.

44-Hidalgo-Cantabrana C, López P, Gueimonde M, Clara G, Suárez A, Margolles A, Ruas-Madiedo P. Immune modulation capability of exopolysaccharides synthesised by lactic acid bacteria and bifidobacteria. Probiotics Antimicrob Proteins 2012; 4 (4): 227-237.

45-Ren L, Reynisson J, Perera C, Hemar Y. The physicochemical properties of a new class of anticancer fungal polysaccharides: A comparative study. Carbohydr Polym 2013; 97 (1): 177-187.

46-Lee WY, Park Y, Ahn JK, Ka KH, Park SY. Factors influencing the production of endopolysaccharide and exopolysaccharide from Ganoderma applanatum. Enzyme Microb Technol 2007; 40: 249-254.

47-Lung MY., Huang WZ. Production, purification and tumor necrosis factor- $\alpha$ (TNF- $\alpha$ ) release capability of exopolysaccharide from Laetiporus sulphureus (Bulliard:Fries), Bondartsev \& Singer in submerged cultures. Process Biochemistry 2011; 46 (2), 433-439.

48-Schepetkin IA, Faulkner CL, Nelson-Overton LK, Wiley JA, Quinn MT. Macrophage immunomodulatory activity of polysaccharides isolated from Juniperus scopolorum. Int Immunopharmacol 2005; 5: 17831799.

49-Liu J, Sun Y, Yu C, Liu L. Chemical structure of one low molecular weight and water-soluble polysaccharide (EFP-W1) from the roots of Euphorbia fischeriana. Food Chem 2012; 87, 1236-1240.

50-Joseph S, Sabulal B, George V, Antony KR, Janardhanan KK. Antitumor and anti-inflammatory activities of polysaccharides isolated from Ganoderma lucidum. Acta pharmaceutica 2011; 61 (3): 335-342.

51-Hong JH, Jung HK. Antioxidant and antitumor activities of $\beta$-glucan-rich exopolysaccharides with different molecular weight from Paenibacillus polymyxa JB115. J Korean Soc Appl Biol Chem 2014; 57 (1): 105-112.

52-Kimura Y, Sumiyoshi M, Suzuki T, Sakanaka M. Antitumor and antimetastatic activity of a novel water-soluble low molecular weight beta-1, 3D-glucan (branch beta-1,6) isolated from Aureobasidium pullulans 1A1 strain black yeast. Anticancer Res 2006; 26 : 4131-4141.

53-Leung MYK, Fung KP, Choy YM. The isolation and characterization of an immunomodulatory and antitumor polysaccharide preparation from Flammulina velutipes. Immunopharmacology 1997; 35: 255-63.

54-Cleary JA, Kelly GE, Husband AJ. The effect of molecular weight and $\beta$-1,6-linkages on priming of macrophage function in mice by $(1,3)-\beta-D-g l u c a n$. Immunol Cell Biol 1999; 77: 395-403.

55-Fernandez de Palencia P, Werning ML., Sierra-Filardi E, Duenas MT, Irastorza A, Corbi A, and Lopez P. Probiotic properties of the 2-substituted $(1,3)-\beta-D$ glucan producing bacterium Pediococcus parvulus 2.6. 
Appl Environ Microbiol 2009; 75: 4887-4891.

56-Garai-Ibabe G, Aeizaga J, Aznar R, Elizaquivel P, Prieto A, Irastorza A, and Duenas MT. Screening and selection of 2-branched (1,3)- $\beta$-D-glucan producing lactic acid bacteria and exopolysaccharide characterization. J Agric Food Chem 2010; 58: 6149-6156.

57-Mueller A, Raptis J, and Rice P. The influence of glucan polymer structure and solution conformation on binding to (1->3)- $\beta$-D glucan receptors in a human monocyte-like cell line. Glycobiology 2000; 10: 339-346.

58-Laiño J, Villena J, Kanmani P, and Kitazawa $\mathrm{H}$. Immunoregulatory effects triggered by lactic acid bacteria exopolysaccharides: new insights into molecular interactions with host cells. Microorganisms 2016; 4(3): 27.

59-Sun L, Wang L, Zhou Y. Immunomodulation and antitumor activities of different-molecular-weight polysaccharides from Porphyridium cruentum. Carbohydrate Polymers 2012; 87 (2): 1206-1210.

60-Zivkovic M, Miljkovic M, Ruas-Madiedo P, Strahinic I, Tolinacki M, Golic N, Kojik M. Exopolysaccharide production and ropy phenotype are determined by two gene clusters in putative probiotic strain Lactobacillus paraplantarum BGCG11. Appl Environ Microbiol 2015; 81: 1387-1396.

61-Matsuzaki C, Hayakawa A, Matsumoto K, Katoh T, Yamamoto K, Hisa K. Exopolysaccharides produced by Leuconostoc mesenteroides Strain NTM048 as an immunostimulant to enhance the mucosal barrier and Influence the systemic Immune response. J Agric Food Chem 2015; 63: 7009-7015.

62-Kitazawa $\mathrm{H}$, Yamaguchi T, Fujimoto $\mathrm{Y}$, Itoh T. An analysis of mitogenic response of phosphopolysaccharide, a B-cell mitogen produced by Lactococcus lactis ssp. cremoris to spleen cells. Animal Sci Technol 1993; 64: 807-812.

63-Kitazawa H, Itoh T, Tomioka Y, Mizugaki M, Yamaguchi T. Induction of IFNy and IL-1a production in macrophages stimulated with phosphopolysaccharide produced by Lactococcus lactis ssp. cremoris. Int J Food Microbiol 1996; 31: 99-106.

64-Mazmanian SK, Round JL, Kasper DL. A microbial symbiosis factor prevents intestinal inflammatory disease. Nature 2008; 453: 620-625.

65-Bleau C, Monges A, Rashidan K, Laverdure JP, Lacroix M, Van Calsteren MR, Millette M, Savard $\mathrm{R}$, and Lamontagne L. Intermediate chains of exopolysaccharides from Lactobacillusrhamnosus RW9595M increase IL-10 production by macrophages. J Appl Microbiol 2010; 108: 666-675.

66-Lehner MD, Morath S, Michelsen KS, Schumann RR, and Hartung T. Induction of cross-tolerance by lipopolysaccharide and highly purified lipoteichoic acid via different toll-like receptors Independent of paracrine mediators. J Immunol 2001; 166: 5161-5167.

67-Liu C-F, Tseng K-C, Chiang S-S, Lee B-H, Hsu W-H, Pan T-M. Immunomodulatory and antioxidant potential of Lactobacillus exopolysaccharides. J Sci Food Agric 2011; 91: 2284-2291.

68-Uemura J, Itoh T, Kasneko T, Noda K. Chemical characterization of extracellular polysaccharide from Lactobacillus delbrueckii subsp. bulgaricus OLL1073R-1. Milchwissenschaft 1998; 53: 443-446.

69-Nishimura-Uemura J, Kitazawa H, Kawai Y, Itoh T, Oda M, Saito T. Functional alteration of murine macrophages stimulated with extracellular polysaccharides from Lactobacillus delbrueckii ssp. bulgaricus OLL1073R-1. Food Microbiol 2003; 20: 267-273

70-Baruah R, Das D, Goyal A. Heteropolysaccharides from lactic acid bacteria: current trends and applications. J Prob Health 2016; 4 (141): 2.

71-Dilna SV, Surya H, Aswathy RG, Varsha KK, Sakthikumar DN, Pandey A, Nampoothiri KM. Characterization of an exopolysaccharide with potential healthbenefit properties from a probiotic Lactobacillus plantarum RJF4. LWT Food Sci Technol 2015: 11791186.

72-Wang J, Zhao X, Yang Y, Zhao A, Yang Z. Characterization and bioactivities of an exopolysaccharide produced by Lactobacillus plantarum YW32. Int J Biol Macromol 2015; 74: 119-126.

73-Gibson GR, Beatty ER, Wang X, Cummings JH. Selective stimulation of bifidobacteria in the human colon by oligofructose and inulin. Gastroenterology 1995; 108: 975-982. 
74-Reddy SK, Pawlik TM, Zorzi D, Gleisner AL, Ribero D, Assumpcao L, Barbas AS, Abdalla EK, Choti MA, Vauthey JN, Ludwig KA, Mantyh CR, Morse MA, Clary BM. Simultaneous resections of colorectal cancer and synchronous liver metastases: a multi-institutional analysis. Ann Surg Oncol 2007; 14: 3481-3491.

75-Hongpattarakere T, Cherntong N, Wichienchot S, Kolida S, Rastall RA. In vitro prebiotic evaluation of exopolysaccharides produced by marine isolated lactic acid bacteria. Carbohydr Polym 2012: 846-852.

76-Grosu-Tudor SS, Zamfir M, Der Meulen RV, Falony G, De Vuyst L. Prebiotic potential of some exopolysaccharides produced by lactic acid bacteria. Roman Biotechnol Lett 2013; 18: 8666-8675.

77-Wang J, Zhao X, Tian Z, He C, Yang Y, Yang, Z. Isolation and Characterization of exopolysaccharide-producing Lactobacillus plantarum SKT109 from Tibet Kefir. Polish J Food Nutri Sci 2015: 269-280.

78-De Vuyst L, Degeest B. Heteropolysaccharides from lactic acid bacteria. FEMS Microbiol Rev 1999; 23: $153-177$.

79-Zhang L, Liu C, Li D, Zhao Y, Zhang X, Zeng X, Yang Z, Li S. Antioxidant activity of an exopolysaccharide isolated from Lactobacillus plantarum C88. Int J Biol Macromol 2013; 54: 270-275.

80-de Vries EG, Gietema JA, de Jong S. Tumor necrosis factorrelated apoptosis-inducing ligand pathway and its therapeutic implications. Clin Cancer Res 2006; 12: 2390-2393.

81-Bucur, O, Ray S, Bucur MC, Almasan A. APO2 ligand/tumor necrosis factor-related apoptosis-inducing ligand in prostate cancer therapy. Front Biosci 2006; 11: 1549-1568.

82-Elmore S. Apoptosis: a review of programmed cell death. Toxicol Pathol 2007; 35: 495-516.

83-Fesik SW. Promoting apoptosis as a strategy for cancer drug discovery. Nat Rev Cancer 2005; 5: 876885.

84-Kato I, Endo K, Yokokura T. Effects of oral administration of Lactobacillus casei on antitumor responses induced by tumor resection in mice. Int $\mathrm{J}$ Immunopharmacol 1994; 16: 29-36.
85-Gozuacik D, Kimchi A. Autophagy as a cell death and tumor suppressor mechanism. Oncogene 2004; 23: 2891-2906.

86-Kondo Y, Kondo S. Autophagy and cancer therapy. Autophagy 2006; 2 (2): 85-90.

87-Di Marzio L, Russo FP, D’Alo S, Biordi L, Ulisse S, Amicosante G, De Simone C, Cifone MG. Apoptotic effects of selected strains of lactic acid bacteria on a human $T$ leukemia cell line are associated with bacterial arginine deiminase and/or sphingomyelinase activities. Nutr Cancer 2001; 40: 185-196.

88-Belury, MA. Inhibition of carcinogenesis by conjugated linoleic acid: potential mechanisms of action. J Nutr 2002; 132: 2995-2998.

89-Li J, Ni M, Lee B, Barron E, Hinton DR, Lee AS. The unfolded protein response regulator GRP78BiP is required for endoplasmic reticulum integrity and stress-induced autophagy in mammalian cells. Cell Death Differ 2008; 15: 1460-1471.

90-Ding WX, Ni HM, Gao W, Hou YF, Melan MA, Chen $X$, Stolz DB, Shao ZM, Yin XM. Differential effects of endoplasmic reticulum stress-induced autophagy on cell survival. J Biol Chem 2007; 282: 4702-4710.

91-Lee YH, Chung MC, Lin Q, Boelsterli UA. Troglitazone-induced hepatic mitochondrial proteome expression dynamics in heterozygous Sod2 (+/-) mice: twostage oxidative injury. Toxicol Appl Pharmacol 2008; 231: 43-51.

92-Shimizu S, Kanaseki T, Mizushima N, Mizuta T, Arakawa-Kobayashi S, Thompson CB, Tsujimoto Y. Role of Bcl-2 family proteins in a non-apoptotic programmed cell death dependent on autophagy genes. Nat Cell Biol 2004; 6: 1221-1228.

93-Pattingre S, Tassa A, Qu X, Garuti R, Liang XH, Mizushima N, Packer M, Schneider MD, Levine, B. $\mathrm{Bcl}-2$ antiapoptotic proteins inhibit Beclin 1-dependent autophagy. Cell 2005; 122: 927-939.

94-Moretti L, Attia A, Kim KW, Lu B. Crosstalk between Bak/Bax and mTOR signaling regulates radiationinduced autophagy. Autophagy 2007; 3: 142-147. 